\title{
Panorama e determinantes da satisfação com os serviços públicos no Brasil
}

Robert Bonifácio e Rogério Schlegel

\section{Introdução}

A avaliação que o brasileiro faz dos serviços públicos é tema pouco explorado em estudos acadêmicos no Brasil, embora tenha características que justificariam atenção especial. De um lado, essa avaliação é um indicador relevante em termos de responsividade porque representa o grau de satisfação do cidadão com a forma como o Estado cumpre algumas de suas tarefas centrais, propiciando serviços como saúde e educação a partir dos impostos extraídos da sociedade. De outro lado, esse é um insumo decisivo para a legitimidade democrática segundo diferentes abordagens teóricas. Os serviços públicos são a face mais concreta do Estado e a principal vitrine do desempenho governamental, de forma que sua avaliação é capaz de impactar de forma indireta a confiança nos políticos e no Executivo (Listhaug; Wiberg, 1998).

Nas democracias, cabe aos governantes o papel de formular e implementar políticas públicas, e a satisfação dos cidadãos com essas iniciativas é considerada 
relevante por impactar a escolha eleitoral e contribuir para a sustentação ou substituição do grupo político no poder. Substantivamente, avaliações positivas sobre serviços públicos também são um indicativo de que ações do poder público para minimizar problemas e melhorar a vida dos cidadãos estão sendo bem-sucedidas. Em última análise, a avaliação dos serviços públicos é dimensão indispensável na análise da qualidade de uma democracia, por significar o quanto governos e instituições são responsivos com as demandas e preferências dos cidadãos (Diamond; Morlino, 2004, p. 21-22). Apesar disso, a satisfação com os serviços públicos não tem recebido a atenção que merece da pesquisa brasileira.

Este artigo pretende contribuir para minimizar essa lacuna e tem dois objetivos: apresentar avaliação dos serviços públicos a partir de dados empíricos e avançar no entendimento de seus determinantes. Um desafio especial foi encontrar pesquisas de opinião que contemplem o tema e permitam a exploração de seus microdados com análises estatísticas mais complexas - o número de surveys que preenchem os pré-requisitos deste trabalho mostrou-se reduzido. Além disso, o Brasil é uma federação com desenho institucional repleto de particularidades $^{1}$ : a distribuição das atribuições estatais tem o formato que se convencionou chamar de marble cake ("bolo de mármore"), com governo central, estados e municípios compartilhando responsabilidades em diversos setores; os municípios são entes federativos independentes, podendo se relacionar diretamente com o governo central, sem a intermediação dos estados; em áreas como saúde, educação e política social, há grande descentralização na implementação de políticas, mas seguindo parâmetros estabelecidos em pormenorizada regulação federal. Essa riqueza e complexidade em geral escapam aos questionários dos surveys disponíveis, que, com frequência, tratam os serviços públicos sem discriminar a esfera $\mathrm{da}$ Federação a que estão ligados.

Nossa avaliação é que, considerando a compreensão incipiente que se tem sobre o objeto no Brasil, essas limitações não prejudicam o caráter exploratório deste estudo. As evidências levantadas indicam que os cidadãos mais escolarizados e informados estão mais insatisfeitos com os serviços públicos e que o contato direto com os serviços pode impactar negativamente a percepção do brasileiro sobre seu funcionamento.

Além desta introdução, este artigo contém quatro seções. Inicialmente apresentamos os dados com que trabalhamos e traçamos um panorama sobre a percepção dos brasileiros em relação a diversos tipos de serviços públicos. Na segunda seção, expomos e discutimos alguns dos principais marcos teóricos a respeito das orientações individuais em relação às instituições públicas. Em seguida, exploramos testes estatísticos visando a relacionar variáveis explicativas com a satisfação com os serviços públicos. Nossas considerações sobre os resultados encontrados aparecem na quarta seção, que finaliza o texto.

\section{Panorama da satisfação dos brasileiros com os serviços públicos}

Neste trabalho, a avaliação dos serviços públicos foi construída a partir da percepção que o cidadão tem sobre eles. Foram procuradas pesquisas sobre o tema em dois dos principais órgãos armazenadores de bancos de dados com finalidades acadêmicas do Brasil - o Consórcio de 
Informações Sociais (CIS), vinculado à Universidade de São Paulo, e o Centro de Estudos em Opinião Pública (Cesop), vinculado à Universidade Estadual de Campinas. Surveys passíveis de uso neste trabalho se mostraram raros. De forma geral, as pesquisas aplicam questões de cunho avaliativo tendo como referência instituições e atores políticos, como o Congresso Nacional, os partidos políticos e o presidente da República. A escassez de pesquisas que avaliem a percepção sobre os serviços públicos implica limitação em termos de variáveis utilizáveis na análise e reduz as oportunidades para comparação dos resultados no tempo.

Foram selecionados para uso os bancos de dados dos seguintes surveys:

1) "Avaliação de seis meses de governo do presidente Itamar Franco", realizado pelo Instituto de Pesquisas Datafolha em março de 1993. A abrangência da pesquisa é nacional e foram entrevistadas 2.526 pessoas.

2) "Estudo eleitoral brasileiro (EsEB)", realizado com financiamento da Coordenadoria de Aperfeiçoamento de Pessoal de Nível Superior (Capes). Trata-se de uma pesquisa de opinião aplicada com 2.514 pessoas de todo o Brasil em período após a realização das eleições de 2002.

3) "A desconfiança dos cidadãos das instituições democráticas", pesquisa fruto do trabalho de diversos pesquisadores filiados à época à Universidade de São Paulo e Universidade Estadual de Campinas, sob coordenação dos Professores José Álvaro Moisés (USP) e Rachel Meneguello (Unicamp). O financiamento da pesquisa se deu por meio da Fundação de Amparo à Pesquisa do Estado de São Paulo (Fapesp) e foram entrevistadas 2004 pessoas em junho de 2006.

4) "Barômetro das Américas", referente ao Brasil nos anos de 2008 e 2010.
Trata-se de uma série de pesquisas de opinião iniciada em meados da década de 1990 e que tem como foco os países da América Latina. O Latin America Public Opinion Project (Lapop), órgão atualmente pertencente à Universidade de Vanderbilt (EUA), é o responsável pela realização da pesquisa. A abrangência é nacional e o número de entrevistados em 2008 foi de 1.497 e, em 2010, de 2.482.

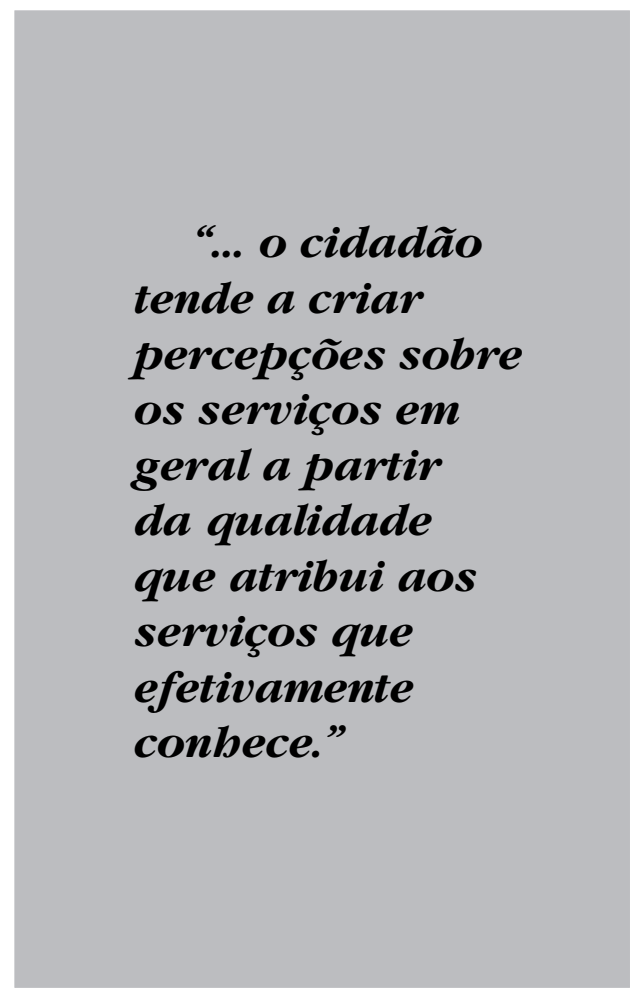

\section{Avaliações dos serviços públicos no Brasil}

No Brasil, há sinais de que a percepção sobre os serviços públicos tenha tido alterações significativas nas últimas décadas. Evidências nesse sentido aparecem na análise de variáveis sobre avaliações gerais dos serviços públicos, a 
respeito de avaliações individualizadas de serviços específicos e relativas a notas atribuídas à qualidade de serviços.

Nas pesquisas de 1993 e 2006, os entrevistados foram questionados sobre os serviços públicos sem indicação de programas, ações específicas ou esfera da federação responsável, gerando indicador de caráter geral, segmentado por setor. Os entrevistados avaliaram os serviços de habitação, polícia, saúde, educação, transportes, seguro-desemprego, tribunais de Justiça, esgotos e saneamento e previdência social. As variáveis utilizadas em ambas as pesquisas apresentam redação e alternativas de resposta semelhantes ${ }^{2}$, o que permite a comparação dos dados. Apenas três casos não são passíveis de comparação: tribunais de Justiça, presentes apenas nos dados de 1993, previdência social e redes de esgotos e saneamento, encontrados somente na pesquisa de $2006^{3}$.

O resultado mais evidente é a elevação da percepção favorável no segundo momento. Em todos os setores compa- rados, a avaliação positiva teve percentuais maiores em 2006 do que em 1993. As maiores diferenças aparecem em educação (elevação de $28,6 \%$ na percepção positiva), habitação (25\%), transportes (24,5\%) e seguro-desemprego (23,2\%). Mas também saúde $(17,75 \%)$ e polícia $(16 \%)$ tiveram incremento de avaliações positivas nesse intervalo de 17 anos.

Com isso, houve mudança notável na direção geral das avaliações nas duas pesquisas: em 1993, há evidente predominância das avaliações negativas e, em 2006, ocorre equilíbrio nas avaliações entre os serviços. Na primeira pesquisa citada, apenas os serviços de transportes e os oferecidos pelos tribunais de Justiça não apresentam a avaliação negativa como preponderante. Nesses casos, porém, a alternativa mais mencionada é a avaliação regular e não a positiva, o que indica que esses serviços não eram necessariamente avaliados positivamente. Já na pesquisa de 2006, habitação, educação, transportes e seguro-desemprego apresentam maiores percentuais de avaliações positivas, enquanto os serviços

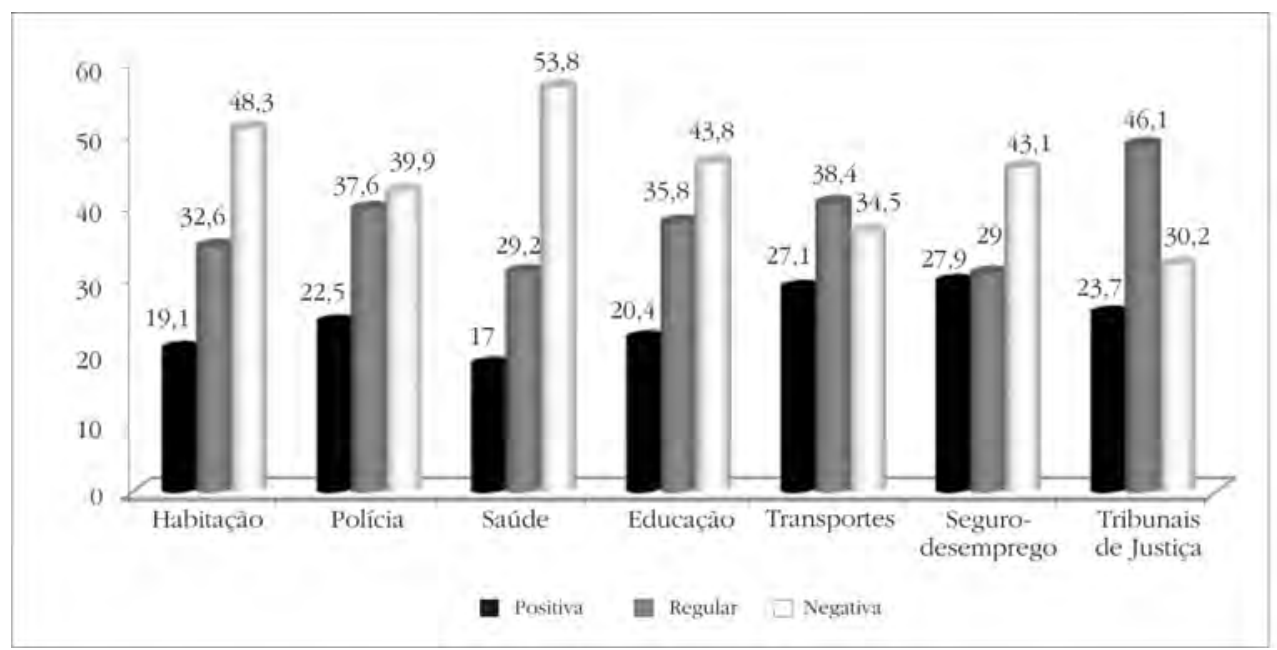

Fonte: "Avaliação de seis meses de governo do presidente Itamar Franco", Datafolha/1993

Gráfico 1: Avaliação de serviços públicos em 1993 (em \%) 


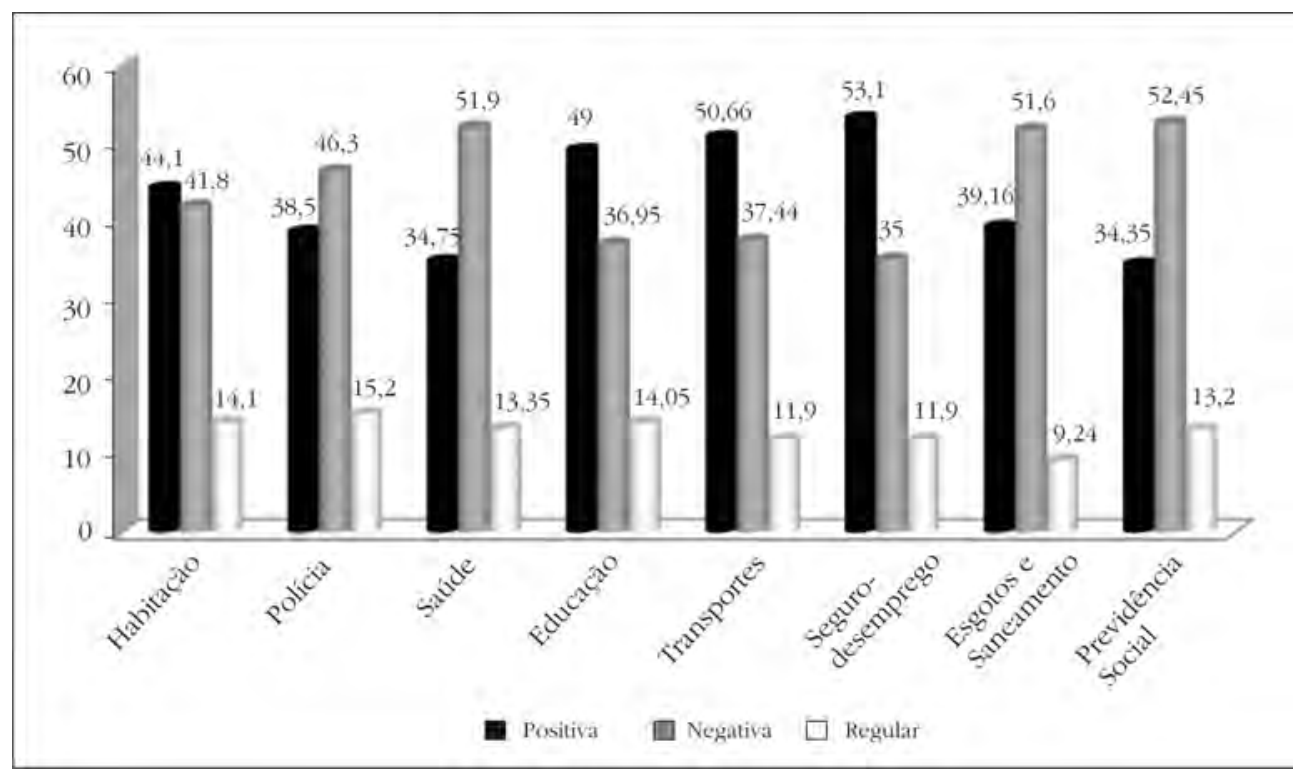

Fonte: A desconfiança dos cidadãos das instituições democráticas/2006

\section{Gráfico 2: Avaliação de serviços públicos em 2006 (em \%)}

de polícia, saúde, esgotos e saneamento e previdência social possuem maiores indicações de avaliações negativas.

É importante frisarmos que, de 1993 para 2006, houve diversas mudanças nas políticas públicas, especialmente as de responsabilidade do governo federal. Há relativo consenso na literatura de que essas mudanças levaram a melhorias das condições de vida dos cidadãos. Houve combate decisivo à inflação e ao descontrole das contas públicas, com a implantação do Plano Real; foi consolidada rede de proteção social que tem como carrochefe o Programa Bolsa-Família, que envolve transferência direta de renda aos cidadãos de renda baixa; o salário mínimo teve sucessivos aumentos reais. Os impactos diretos - via reorganização da máquina do Estado e aumento da disponibilidade orçamentária - e indiretos - com alterações na percepção da população sobre o Estado, favorecida pelo aumento da riqueza e redução da pobreza e da desigualdade - podem explicar esse primeiro achado.

Ainda é relevante mencionar a flutuação observada na avaliação regular e a questão metodológica que pode ajudar a entender isso. Nos dados de 1993, os níveis de respostas "regular" variam de $17 \%$ a $27,9 \%$ das respostas válidas, enquanto em 2006 a variação é entre $9,24 \%$ e $15,2 \%$, dependendo do setor. Ou seja, o maior percentual desse tipo de resposta na pesquisa mais recente sequer alcança o menor percentual existente na pesquisa de 1993. Uma explicação para isso pode residir no fato de que, na pesquisa mais antiga, a opção de resposta "regular" era dada como alternativa ao entrevistado, enquanto, na pesquisa de 2006, tal opção de resposta era espontânea, ou seja, o entrevistado não sabia de sua possibilidade, apenas a indicava caso a achasse a mais conveniente para o questionamento feito. Segundo Fowler Junior (1995), é comum o 
entrevistado ficar "em cima do muro" quando é colocado para avaliar e/ou julgar algo ou alguém. Por isso, quando se deseja extrair dos entrevistados posicionamentos mais esclarecedores e objetivos, é desejável não citar como alternativa de resposta opções que expressam posicionamento de meio termo.

\section{Avaliações específicas de serviços públicos}

Em duas das pesquisas de opinião utilizadas, as avaliações têm caráter mais específico, referindo-se a serviços sob responsabilidade da administração municipal. No Eseb 2002, a maioria dos serviços avaliados tem esse traço, ainda que o enunciado da questão não mencione isso diretamente. Já no Barômetro das Américas de 2008 e 2010, o questionário se refere expressamente aos serviços prestados pela prefeitura municipal ${ }^{4}$.

A partir da leitura de dados do gráfico 3, observamos que as considerações sobre todos os serviços avaliados são predominantemente positivas. Essa constatação encontra maior sustentação nos dados relativos à coleta de lixo, em que $71,6 \%$ dos entrevistados consideram que a qualidade do serviço merece uma nota alta, compreendida entre 7 e 10 . O controle de camelôs, mesas de bar e bancas de lojas é o serviço com menor percentual de notas altas $(34,5 \%)$ e a avaliação dos serviços de saúde é a que apresenta menor diferença entre as maiores e menores notas $(1,6 \%)$.

Os resultados apresentam tendência oposta às avaliações gerais de serviços públicos, presentes na pesquisa de 1993, e também diferem do equilíbrio das avaliações gerais indicadas na pesquisa de 2006.
Quando nos atemos aos resultados referentes às avaliações de serviços públicos municipais em 2008 e 2010 (Gráfico 4), a tendência de avaliação positiva também se mostra presente. No primeiro ano citado, mais da metade dos entrevistados (51,3\%) dá indicações positivas quanto à qualidade dos serviços públicos. Em 2010, o cenário é um pouco distinto, já que as avaliações regulares predominam $(42,4 \%)$, mas as avaliações positivas ficam em segundo lugar $(32,9 \%)$.

\section{Qualidade dos serviços públicos em avaliação comparativa}

Algumas variáveis usadas para medir a percepção do cidadão sobre os serviços públicos fogem do usual, ou seja, da captação das percepções de qualidade dos serviços, adicionando um elemento externo no qual o entrevistador deve se basear para fazer sua avaliação. No Eseb 2002, encontramos duas variáveis com essa característica. Uma delas busca extrair dos entrevistados uma nota ao serviço público brasileiro, tendo como base de comparação uma rede de serviço público ideal, nota 10 , e uma rede pior possível, nota zero ${ }^{5}$. Observamos que as indicações concentramse com mais intensidade nas notas que entendemos pertencer à categoria regular de avaliação (de 4 a 6 ) e que as notas que expressam os extremos positivo e negativo (10 e 0 , respectivamente) estão longe de serem as mais citadas. Os valores da moda $(5,0)$ e da média $(5,59)$ reforçam a tendência de visão de qualidade regular dos serviços públicos nessa avaliação comparativa.

Outra variável trata dos serviços públicos levando em conta o que é cobrado como imposto, explicitando que os primeiros são mantidos com os tributos arrecadados. O entrevistado é questionado 


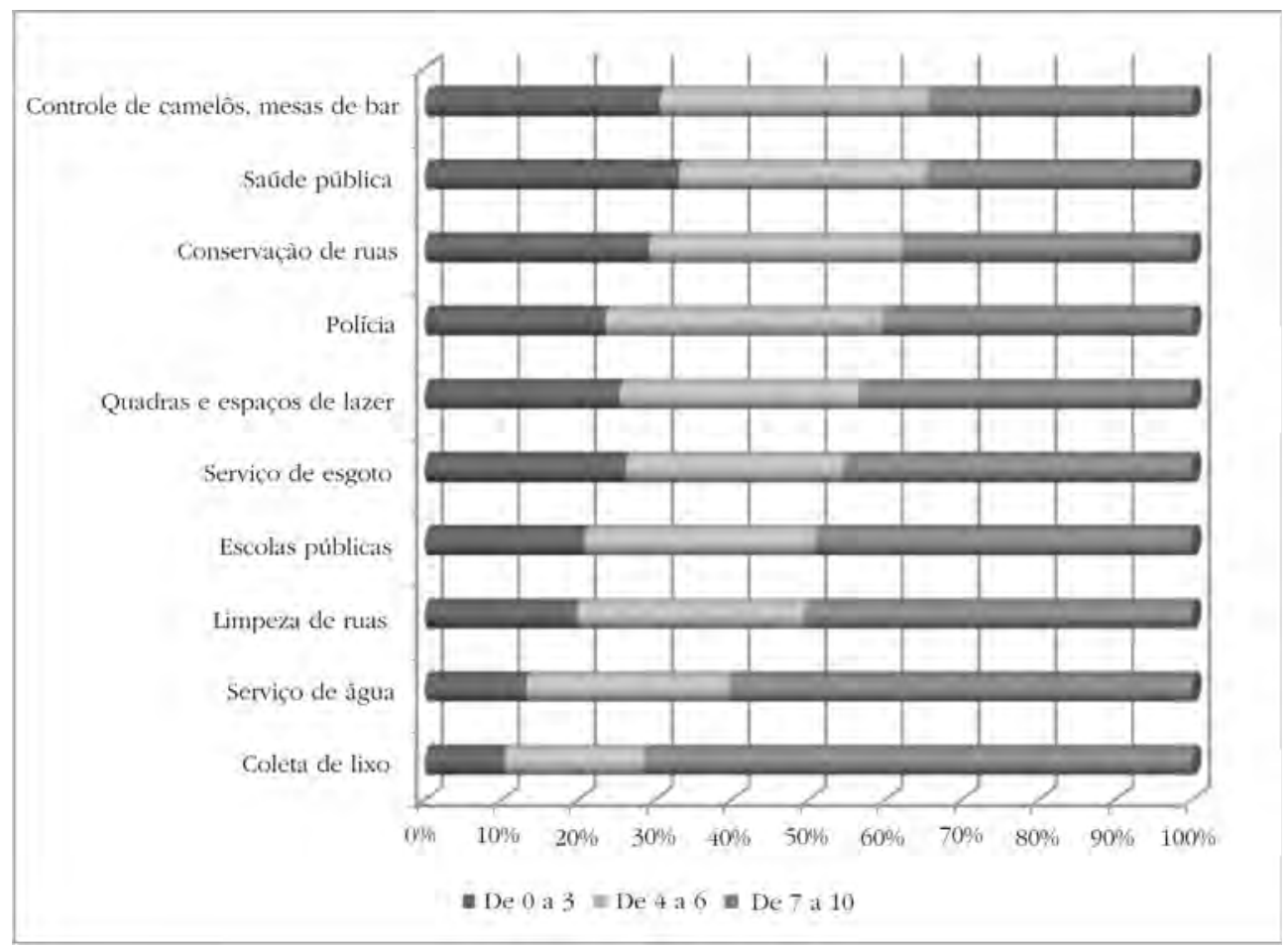

Fonte: Eseb/2002

Gráfico 3: Avaliações de serviços públicos específicos (2002)

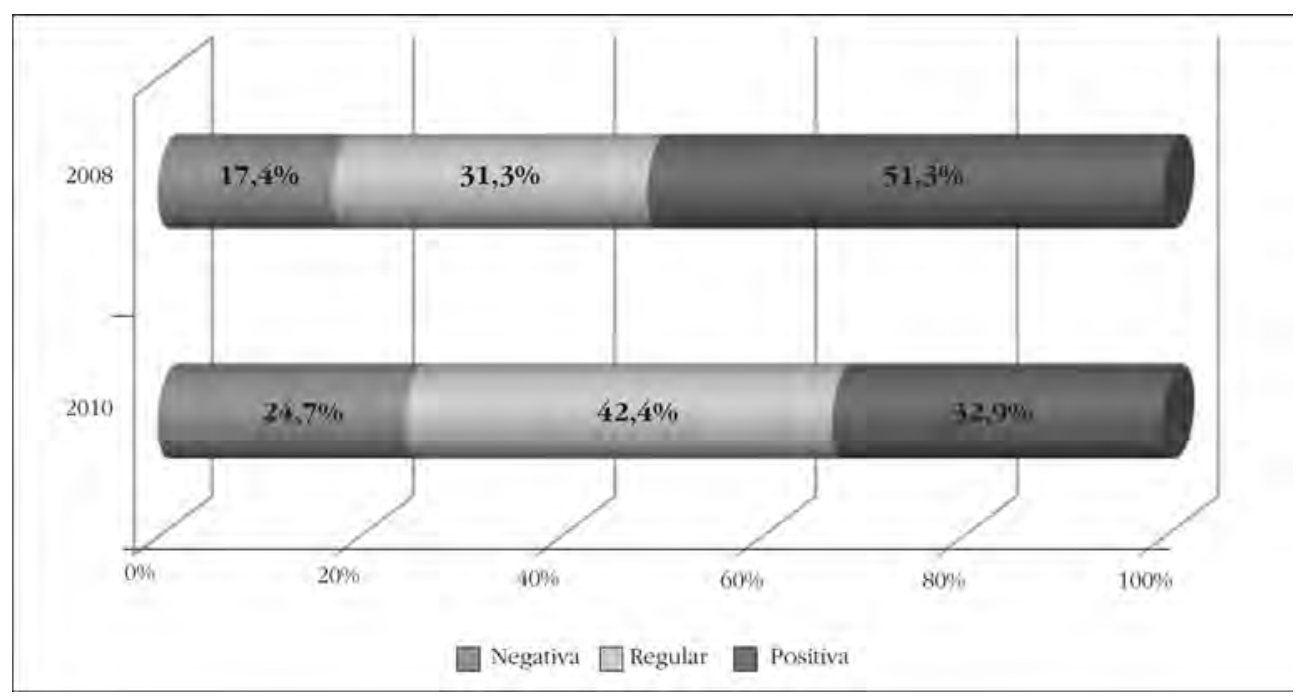

Fonte: Barômetro das Américas/2008 e 2010

Gráfico 4: Avaliação dos serviços públicos municipais em 2008 e 2010 (em \%) 


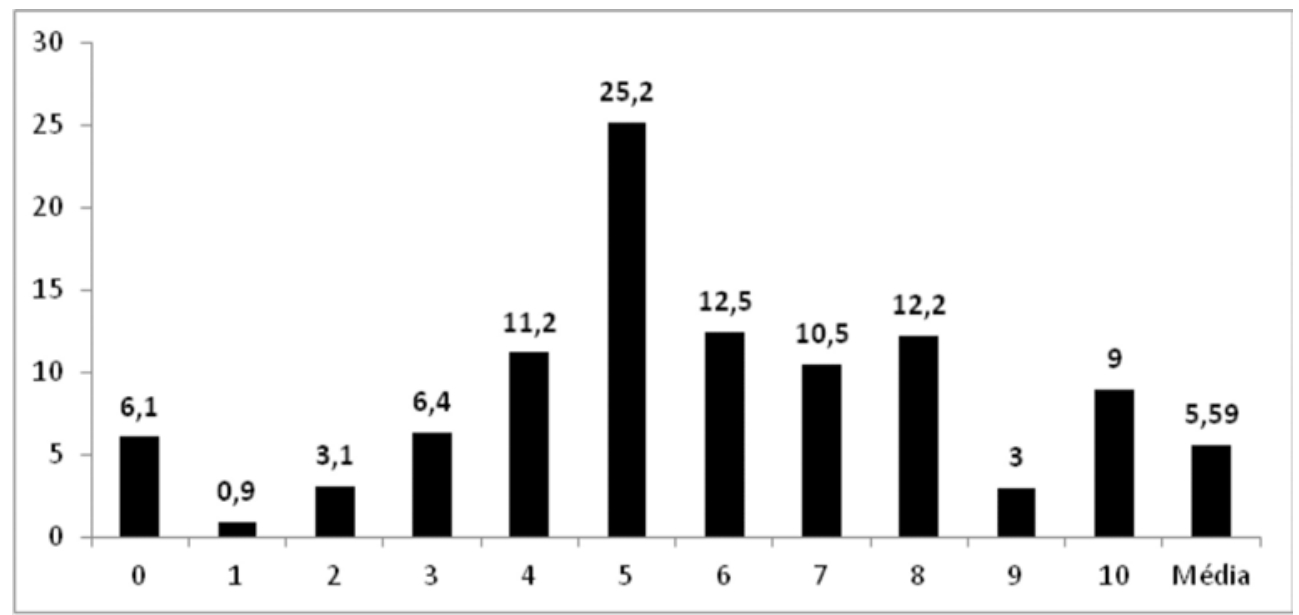

Fonte: Eseb/2002

Nota: Nesse gráfico, os valores das notas são percentuais e o valor da média é numérico. Respostas "não sei" e "não quero responder" dadas pelos entrevistados foram excluídas do conjunto de respostas válidas.

Gráfico 5: Qualidade dos serviços públicos comparados à rede ideal (2002)

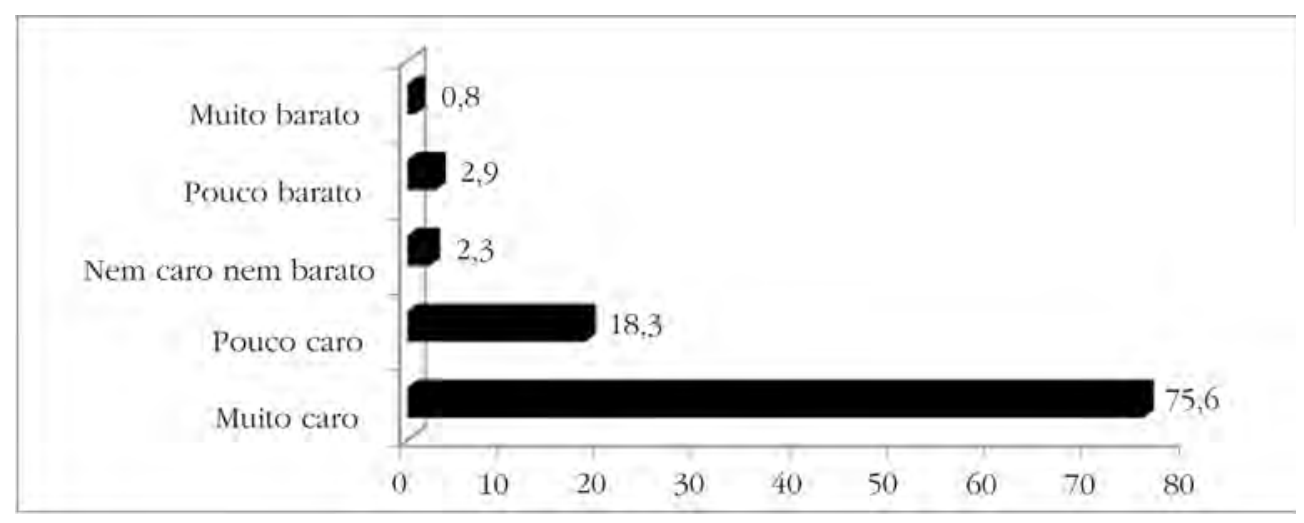

Fonte: Eseb/2002

Gráfico 6: Avaliação dos impostos conforme qualidade dos serviços públicos $(2002$, em \%) 
se acha que os impostos são caros ou baratos, considerando a qualidade dos serviços públicos ofertados. Os dados revelam insatisfação: mais de $3 / 4$ dos entrevistados consideram pagar muito caro pelos impostos.

\section{Determinantes da satisfação com os serviços públicos}

Este estudo pretende contribuir para o entendimento mais apurado da percepção do cidadão sobre os serviços públicos - área em que, como já observamos, há relativa escassez de trabalhos acadêmicos sobre o contexto brasileiro. $\mathrm{Na}$ Ciência Política, estudos que visam a entender as avaliações individuais privilegiam as instituições e atores políticos, como o Congresso Nacional, partidos políticos e representantes políticos. Esses trabalhos inspiram nossas hipóteses básicas e desenho de pesquisa, por tratarem de aspectos correlatos da percepção individual. Três grupos de determinantes do comportamento do cidadão merecem destaque nessas pesquisas e são explorados em nosso trabalho: características socioeconômicas e demográficas; acesso às informações e conteúdos midiáticos; e o contato com serviços públicos.

\section{Características socioeconômicas e demográficas}

A condição socioeconômica do cidadão merece ser observada, sobretudo por sua ligação com a hipótese do cidadão crítico, avançada por autores como Inglehart (1999) e Norris (1999). O argumento central de ambos é o de que a mobilização cognitiva gera cidadãos com olhares mais rigorosos para as instituições e o funcionamento dos governos. Norris consolidou a expressão "cidadão crítico" (critical citizen) para designar o tipo bem informado que avalia positivamente a democracia, mas é severo no julgamento do funcionamento concreto de suas agências e regras. Ele seria fruto de maior escolarização e informação sobre o sistema político e os negócios públicos, detectadas especialmente nos países pós-industriais e de democracia mais antiga. Inglehart teorizou sobre o pós-materialismo, uma síndrome atitudinal que teria emergido em consequência do desenvolvimento econômico e que envolve comportamento mais questionador em relação a instituições de diversas características, inclusive as governamentais.

Moisés e Carneiro (2010) sustentam que, para entender a desconfiança política dos cidadãos de alguns países da América Latina, é necessário ter entre os elementos explicativos os relativos à situação socioeconômica das pessoas. De modo mais preciso, seus achados indicam que gênero e escolaridade são os fatores mais importantes desse conjunto de variáveis; são os homens e os mais instruídos aqueles que possuem maiores níveis de desconfiança. Para os autores, isso indica que os menos instruídos e, consequentemente, com baixos níveis de cognição, apresentam perspectiva mais acrítica do funcionamento das instituições democráticas, ocorrendo o inverso com os mais escolarizados.

O trabalho de Figueiredo, Torres e Bichir (2006), por sua vez, constatou que a avaliação dos serviços públicos tornavase mais positiva à medida que diminuía a escolaridade do entrevistado nos surveys que utilizaram para avaliar a conjuntura social brasileira - uma edição de 1991, coordenada por Faria (1992), e outra em 2004, tendo como universo amostral moradores dos domicílios entre os $40 \%$ mais pobres 
da cidade de São Paulo. "As notas atribuídas aos serviços foram relativamente elevadas nos dois surveys, e tanto mais elevadas quanto menor a escolaridade" (Figueiredo; TORRES; Bichir, 2006, p. 179).

Nossa expectativa inicial, portanto, é que cidadãos com posicionamento mais central em termos sociais ou econômicos - com melhor renda ou residindo em municípios maiores -, assim como aqueles com atributos pessoais que representam maior mobilização cognitiva, como escolaridade, apresentem julgamentos mais negativos dos serviços públicos. Por conta disso, analisaremos como o perfil socioeconômico e demográfico impacta a satisfação com os serviços públicos.

\section{Acessos a conteúdos e informações midiáticas}

A mídia é ingrediente que também merece atenção especial quando se trata de entender as relações que o cidadão estabelece com as instituições. $\mathrm{O}$ potencial da mídia para influenciar a percepção dos serviços públicos guarda relação com a centralidade que a comunicação de massa ocupa nas sociedades contemporâneas.

Importante observar que, no que diz respeito a instituições, o sentido dos efeitos específicos da mídia não foi estabelecido de forma inequívoca pela literatura da área. De um lado, a acusação de que os meios de comunicação favorecem a desconfiança política e a desmobilização tem o endosso de gerações de pesquisadores (RoBINSON, 1976; Patterson, 1993; CAPELla; Jamieson, 1997; Putnam, 1995; 2001). Nessa abordagem, o principal argumento é que a mídia cria uma representação das instituições que é especialmente crítica e negativa. No entanto, há evidências de que a exposição à mídia pode afetar o indivíduo também de forma positiva. Ela ampliaria seu nível de informação, interesse pela política e eficácia subjetiva - isto é, a crença de que é capaz de influir na política - e diminuiria os custos para participar da vida pública. Isso se verificaria de maneira mais consistente no caso da exposição à mídia jornalística, e não à mídia em geral (Newton, 1999; Norris, 1996; 2000).

No Brasil, estudos levantaram evidências de que a comunicação de massa não afeta o apoio às instituições em apenas um sentido. Schlegel (2005) encontrou associação positiva entre exposição à mídia jornalística e julgamento "de fundo", não imediato $^{6}$, de políticos e partidos em 2002. No caso da avaliação da atuação de Congresso, governo e partidos, a associação foi negativa. Mesquita (2008) constatou que, mesmo diante de cobertura com valência negativa para o governo federal envolvendo o escândalo do Mensalão em 2005, a audiência ao Jornal $\mathrm{Nacional}^{7}$, em 2006, estava positivamente associada à satisfação com a democracia e à confiança no governo, no presidente da República, nas Forças Armadas, no Poder Judiciário, nos empresários e nos bombeiros. O trabalho também apurou influência do patamar de audiência à televisão em geral, medida em horas, sobre os efeitos do Jornal Nacional. O impacto do telejornal foi mais intenso quando era maior sua participação na "dieta diária" de consumo de televisão do indivíduo - um achado indicando a pertinência de discriminar entre uso da mídia em geral e uso da mídia jornalística no Brasil.

$\mathrm{Na}$ avaliação do papel da mídia como fator com impacto na avaliação dos serviços públicos, consideramos fundamental levar em conta que a exposição aos meios de comunicação é mediada pela experiência e pelos valores pessoais. Ao sintetizar 
décadas de estudos empíricos, autores como Graber (1989) e Klapper (1990) ressaltam que a influência da mídia sobre as opiniões é menor nos casos em que os indivíduos possuem contato direto com o objeto em análise. A influência da mídia também seria mais reduzida em situações em que há opiniões formadas e elas envolvem valores centrais do indivíduo. Nesses casos, o usuário de mídia pode até se expor seletivamente, evitando mensagens que conflitem com suas convicções.

Espera-se que maior interesse em se informar esteja associado à avaliação mais crítica dos serviços públicos, que maior exposição à mídia em geral também incline $\mathrm{a}$ percepção a se tornar mais negativa e que, por outro lado, a exposição à mídia jornalística favoreça visão mais positiva sobre o funcionamento das agências do Estado.

\section{Contatos com os serviços públicos}

O uso efetivo de serviços públicos é a dimensão mais instrumental que iremos avaliar. Estudo do Instituto Mori (2003) apurou que contatos diretos têm efeitos destacados sobre a confiança depositada em organizações prestadoras de serviços públicos do Reino Unido. O trabalho identificou que cidadãos britânicos que tiveram contato direto com serviços de hospital público, conselhos locais e polícia são mais confiantes em relação a esses serviços. A associação se verificou independentemente do contato ter sido considerado positivo ou negativo pelo cidadão (informação não disponível no estudo). Mas é plausível supor que uma ou mais experiências positivas com dado serviço público tendam a melhorar a percepção do cidadão sobre essa agência como um todo.

Para o Brasil, Bonifácio (2009) avaliou o impacto da experiência pessoal para a percepção sobre saúde pública, polícia e transportes, e os resultados não indicaram influência com sentido claro. No caso da polícia, aqueles que usaram seus serviços os avaliaram mais negativamente; para hospitais públicos, o uso teve impacto positivo na avaliação do cidadão; e não houve associação com significância estatística para o caso do transporte público.

Também é plausível pensar que haja "contaminação" da avaliação de outros serviços a partir da experiência vivida com uma determinada agência. A concepção de atalho cognitivo (Popkin, 1994; Lupia, 2005) nos faz supor que o cidadão tende a criar percepções sobre os serviços em geral a partir da qualidade que atribui aos serviços que efetivamente conhece. Isso significa que é realista imaginar que os cidadãos que se utilizam de transporte público e serviços de saúde pública tendem a avaliar todos os demais serviços públicos, como segurança, limpeza e educação, com base na qualidade que atribuem aos serviços que efetivamente conhecem.

O acesso e uso dos serviços públicos foram observados com a presunção de que favoreçam percepção mais positiva do funcionamento das agências, a exemplo do que ocorre no Reino Unido (Mori, 2003). Embora existam grandes déficits na prestação desses serviços, mesmo em áreas de maior desenvolvimento das capacidades estatais (Figueiredo; Torres; Bichir, 2006), acreditamos que o contato com os serviços públicos possa estar associado à avaliação mais positiva.

\section{Procedimentos de análise e resultados}

Nos testes empíricos, nos concentramos nos dados sobre percepção dos serviços públicos contidos na pesquisa de 
2006 - "A desconfiança dos cidadãos das instituições democráticas". Esse banco de dados é o que contém o mais rico acervo entre os disponíveis, seja em relação à variável dependente - é a que possui maior quantidade de serviços postos em análise - ou às variáveis independentes - o conjunto de variáveis é o mais completo para explorar as conexões com características individuais diversas.

Optamos por criar um indicador para o agregado das dimensões envolvidas - um índice de satisfação com os serviços públicos em geral. Para isso, é necessário cobrir duas condições: demonstrar as associações lógicas e estatísticas entre as variáveis relativas à percepção dos serviços. O primeiro quesito é quase que evidente, uma vez que o Estado oferta todos esses serviços para a população, alguns de forma universalizada e outros destinados a grupos específicos. Para demonstrar associação estatística entre as variáveis, utilizamos o teste de análise fatorial ${ }^{8} \mathrm{com}$ o método de extração Principal Axis Factoring - especialmente útil quando as variáveis não apresentam distribuição normal bem definida, como é o caso (Costelo; Osborne, 2005). Também analisamos o alpha de Cronbach, um indicador de consistência interna do fator. Quanto maior o valor do alpha, maior é a correlação entre os itens que compõem o fator e, por consequência, maior a correlação e inter-relacionamento entre as variáveis (CRONBACH, 1951). Os resultados aparecem na Tabela 1.

Verificamos que há, de fato, uma dimensão latente na percepção de todos os serviços públicos. As variáveis tiveram carga sempre superior a 0,4 no fator principal, acima do limiar usualmente adotado para validar a inclusão de variáveis em índices (Garson, 2010). O Alpha de Cronbach acima de 0,8 aponta para elevada consistência interna entre as variáveis e também ratifica a viabilidade de trabalhar com um indicador sintético (GARSON, 2011).

Tabela 1: Análise fatorial e Alpha de Cronbach da avaliação de serviços públicos

\begin{tabular}{l|c}
\hline & Fator \\
\hline Habitação & $\mathbf{1}$ \\
\hline Polícia & 0,614 \\
\hline Saúde & 0,598 \\
\hline Educação & 0,719 \\
\hline Transportes públicos & 0,689 \\
\hline Seguro-desemprego & 0,601 \\
\hline Esgotos e saneamento & 0,482 \\
\hline Previdência social & 0,579 \\
\hline
\end{tabular}

Alpha de Cronbach $=0,835$

Fonte: A desconfiança dos cidadãos das instituições democráticas/2006 
O passo seguinte consistiu em dicotomizar as variáveis originais de avaliação de serviços públicos, de modo a atribuir valor zero às opções de resposta que indicam avaliação negativa (respostas "péssimo" e "ruim") ou regular (resposta "regular") e atribuir valor 1 às que indicam avaliação positiva (respostas "ótimo" e "bom"). Combinar a avaliação média (regular) à negativa se explica pela nossa opção em avaliar a satisfação com os serviços públicos. As respostas "não sei" e "não respondeu" foram excluídas da análise.

Por meio da soma simples das variáveis recodificadas, chegamos ao índice de satisfação com os serviços públicos, com valores de zero a oito. O índice foi posteriormente classificado em três categorias definidas arbitrariamente: valores de 0 a 2 indicam os cidadãos "insatisfeitos"; de 3 a 5, os "moderados"; e de 6 a 8, os brasileiros "satisfeitos" com os serviços do Estado. Essa opção mostrou de fato discriminar os cidadãos, gerando três grupos com proporções significativas. Há maior concentração no grupo dos insatisfeitos, com 41\% da amostra válida; em seguida aparecem os moderados, com $34,1 \%$; os satisfeitos somam 24,9\% (Gráfico 7).

Após essa análise descritiva, passamos para a inferencial, utilizando modelos de regressão logística multinomial com o intuito de verificar, no conjunto de variáveis independentes, quais são estatisticamente significantes e quais os pesos relativos de cada variável para explicar a satisfação dos cidadãos brasileiros com os serviços públicos. Trabalhamos com três grupos de variáveis independentes, descritos abaixo:

1) Características socioeconômicas e demográficas: variáveis que indicam o tipo de município em que habita o entrevistado (se capital, região metropolitana ou interior), sua escolaridade, renda familiar, sexo, idade e cor da pele;

2) Acesso a conteúdos e informações midiáticas: três variáveis que mensuram dimensões diferentes: a atenção dada a notícias de política na televisão; o consumo diário de televisão em geral e a exposição semanal ao Jornal Nacional;

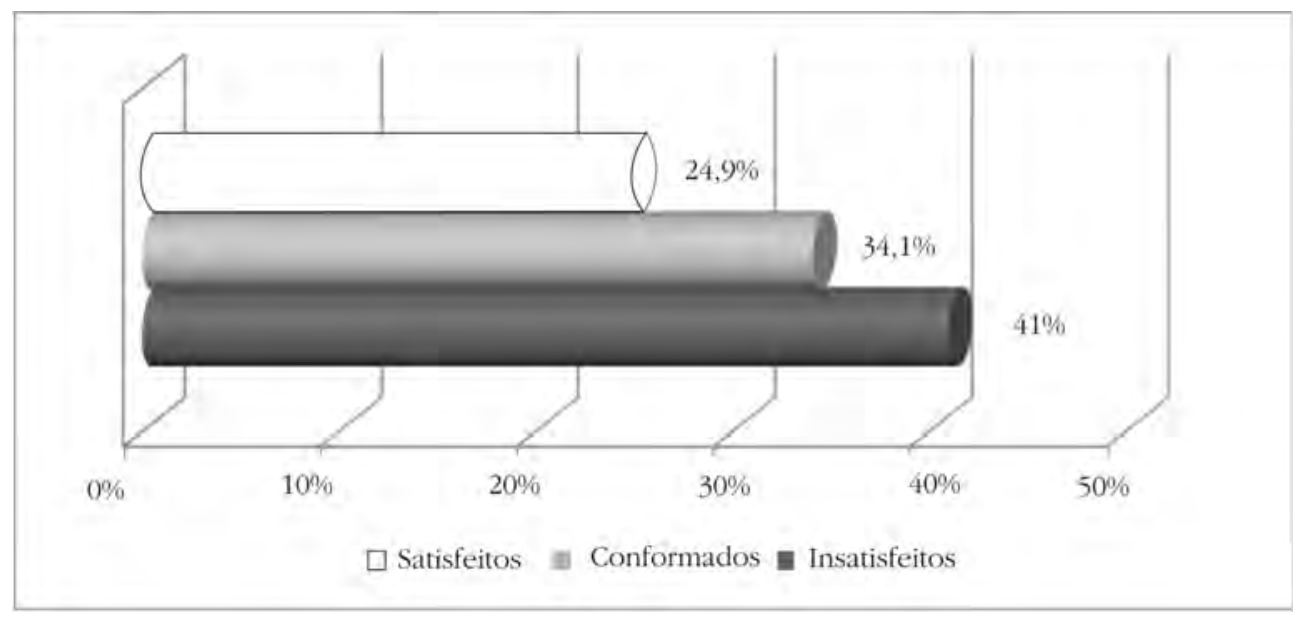

Fonte: A desconfiança dos cidadãos das instituições democráticas/2006

Gráfico 7: Índice de satisfação com os serviços públicos em 2006 (em \%) 
3) Contato direto com os serviços públicos: variáveis que indicam se o indivíduo procurou algum órgão público municipal, estadual ou federal ao longo do ano anterior à realização da pesquisa e variáveis que registram a utilização de três serviços públicos específicos (de transportes, polícia e hospital público).

Os dados dos dois modelos de regressão logística multinomial estão organizados de modo que a percepção dos cidadãos insatisfeitos é a categoria de referência. Assim, os efeitos das variáveis independentes em cada um dos modelos (um referente aos moderados e outro, aos brasileiros satisfeitos) têm de ser interpretados de forma comparada, sempre em relação à avaliação mais negativa. Os resumos das regressões aparecem nos quadros 1 e $2^{9}$.

Quatro variáveis explicativas apresentam significância estatística para a predição de um brasileiro que estamos qualificando como moderado: local de residência; instrução, cor e atenção a notícias sobre política na televisão. Os cidadãos que moram em cidades que são capitais ou fazem parte da região metropolitana apresentam 41,9\% mais chances de serem moderados na percepção dos serviços públicos, quando comparados com aqueles que moram em cidades do interior. Quanto à instrução, observamos que possuir ensino médio (incompleto ou completo) diminui em $31,3 \%$ a chance de o entrevistado ser conformado, quando comparado com os analfabetos ou pessoas com até o ensino primário incompleto. A direção da razão de chance é a mesma no caso dos que possuem ensino superior (incompleto ou completo), mas a intensidade é maior, atingindo a taxa de 47,9\%. No que toca à cor da pele, os dados apontam que os pardos apresentam 40,7\% mais chances de serem moderados, tendo como referencial os pretos.

Há sinal evidente de que maior escolaridade e informação - ou melhor, disposição de se informar, expressa pela variável relativa à atenção dada pela pessoa às notícias sobre política - associam-se negativamente à satisfação com os serviços públicos. Foi clara a tendência de os indivíduos com instrução mais elevada avaliarem pior os serviços públicos - justamente a dimensão socioeconômica descrita nos trabalhos de campo como tendo maior associação com a mobilização cognitiva que marca o endurecimento dos critérios de julgamento de órgãos e práticas do Estado.

Sinais na mesma direção foram obtidos no modelo de regressão da condição de satisfeito (Quadro 2). Praticamente todas as variáveis estatisticamente significantes se mantêm, e com efeito substancialmente mais forte nesse teste. Assim, escolaridade mostrou favorecer comportamento mais crítico, estimulando avaliação negativa em comparação à positiva. Entre as variáveis de mídia, novamente foi "alguma ou muita atenção às notícias" sobre política na televisão que mostrou impactar a satisfação, diminuindo as chances de o indivíduo se mostrar satisfeito com os serviços públicos.

Os resultados para local de residência e cor da pele podem ser entendidos levando em conta a oferta mais do que o perfil da demanda pelos serviços públicos. Morar em áreas mais cosmopolitas, como áreas metropolitanas, e ter pele parda apareceram como favorecendo a condição de moderado em detrimento da condição de insatisfeito, no primeiro modelo de regressão. É plausível pensar que cidadãos que moram em regiões de maior centralidade geográfica - capitais e regiões metropolitanas -, assim como em áreas com menor 
Quadro 1: Preditores da condição de “moderado” (2006)

\begin{tabular}{|c|c|c|c|c|c|}
\hline Variáveis & B & $\begin{array}{l}\text { Erre } \\
\text { padrão: }\end{array}$ & Pvalor & $\begin{array}{l}\text { Razão } \\
\text { de } \\
\text { chance }\end{array}$ & $\begin{array}{l}\text { Efeito } \\
\text { percentual }\end{array}$ \\
\hline Intercepto & -0.737 & 0.387 & 0,057 & & \\
\hline \multicolumn{6}{|l|}{ Municipio (referência: interior) } \\
\hline Capiral ou região metropolitana & 0,350 & 0,135 & $0,010^{20}$ & 1,419 & $41,90 \%$ \\
\hline \multicolumn{6}{|l|}{ Gênero (referência: Feminino) } \\
\hline Masculino & 0,097 & 0,125 & 0,438 & 1,102 & $10,2 \%$ \\
\hline \multicolumn{6}{|l|}{ Idade (referência: 16-24) } \\
\hline $25-34$ & 0,187 & 0,188 & 0,318 & 1,206 & $20,6 \%$ \\
\hline $35-44$ & $-0,010$ & 0,204 & 0,963 & 0,991 & $-0,9 \%$ \\
\hline 45.59 & 0.157 & 0,210 & 0,453 & 1.170 & $17 \%$ \\
\hline 60 ou mais & 0,037 & 0,260 & 0,887 & 1,038 & $3,8 \%$ \\
\hline \multicolumn{6}{|c|}{ Instruçào (referência: até primário incompleto) } \\
\hline Primário completó & $-0,098$ & 0,226 & 0,665 & 0,907 & $-9.3 \%$ \\
\hline Fundamental incompleto completo & -0.172 & 0,199 & 0,387 & 0.842 & $-15.8 \%$ \\
\hline Médio incompleto completo & -0.376 & 0,205 & $0.067^{*}$ & 0.687 & $-31,3 \%$ \\
\hline Superior incompleto ou mais & -0.653 & 0,272 & $0,017^{7 * 4}$ & 0.521 & $-47,9 \%$ \\
\hline \multicolumn{6}{|l|}{ Rendafamiliar (referência: baixa) } \\
\hline Média & 0,185 & $0,1+1$ & 0,200 & 1,203 & $20,3 \%$ \\
\hline Alta & 0,085 & 0,193 & 0,660 & 1.088 & $8,8 \%$ \\
\hline \multicolumn{6}{|l|}{ Cor da pele (referênciat pretos) } \\
\hline Pardos & 0,341 & 0,199 & $0,086^{\circ}$ & 1,407 & $40,7 \%$ \\
\hline Brancos & 0.333 & 0,205 & 0,105 & 1,395 & 39,596 \\
\hline \multicolumn{6}{|c|}{ Exposição à TV em geral (referência: Nâo assistel até 1 bora por dia) } \\
\hline De 2 até 3 horas & 0,160 & 0,157 & 0,308 & 1.173 & $17,3 \%$ \\
\hline Até 4 horas ou mais & 0,272 & 0,174 & 0,118 & 1,312 & $31,2 \%$ \\
\hline \multicolumn{6}{|c|}{ Atencào a noticias sobre política na TV (referencia: Nenbuma) } \\
\hline Pouca & $-0,071$ & 0,151 & 0,639 & 0,932 & $-6,8 \%$ \\
\hline Alguma muita & -0.337 & 0,161 & $0,037^{* 4}$ & 0,714 & $-28,6 \%$ \\
\hline \multicolumn{6}{|c|}{ Exposiçao ao JN (referência: Nâo assiste/ 1 dia na semana) } \\
\hline 2 ou 3 dias & $-10,154$ & 0.192 & 0,721 & 0.857 & $-14,3 \%$ \\
\hline De 4 a todos os dias & 0,151 & 0.178 & 0.396 & 1,163 & $16.3 \%$ \\
\hline \multicolumn{6}{|c|}{ Procurou serviço público ano passado (referência: nầo) } \\
\hline Sim & $-0,199$ & 0,133 & $0,13 \dot{4}$ & 0,819 & $-18,1 \%$ \\
\hline \multicolumn{6}{|c|}{ Utilizou serviços de hospital público (referência: nâo) } \\
\hline Sim & 0,020 & 00,153 & 0,894 & 1,021 & $2,1 \%$ \\
\hline \multicolumn{6}{|c|}{ Utilizou serviços de policia (referéncia: nâo) } \\
\hline Sim & 0,008 &, 160 & 0,961 & 1,008 & $0,8 \%$ \\
\hline \multicolumn{6}{|c|}{ Ltilizou serviços de transporte público (referência: não) } \\
\hline Sim & 0,130 & 0,160 & 0,415 & 1,139 & $13,9 \%$ \\
\hline
\end{tabular}

Fonte: A desconfiança dos cidadãos das instituições democráticas/2006

concentração de pessoas de pele negra, sejam atendidos por serviços de melhor qualidade. Isso ocorreria por conta de desigualdades na distribuição espacial das agências estatais ou da qualidade do atendimento que prestam - sendo as áreas menos centrais e as mais habitadas por pessoas de pele negra associadas à maior carência e precariedade de serviços. Como nosso estudo não se debruçou sobre indicadores objetivos para o desempenho dos serviços públicos, essa é uma hipótese a ser testada em estudos com desenho de pesquisa diferente, que possam quantificar o impacto do desempenho concreto na avaliação subjetiva do cidadão. 


\section{Quadro 2: Preditores da condição de satisfeito (2006)}

\begin{tabular}{|c|c|c|c|c|c|}
\hline Variáveis & B & $\begin{array}{l}\text { Erre } \\
\text { padrào }\end{array}$ & P valor & $\begin{array}{l}\text { Razōes } \\
\text { de } \\
\text { chance }\end{array}$ & $\begin{array}{l}\text { Efeito } \\
\text { percentual }\end{array}$ \\
\hline Intercepto & $-1,243$ & 0,446 & 0.005 & & \\
\hline \multicolumn{6}{|l|}{ Municipio (referência: Interion) } \\
\hline Capital ou regiâo metropolitana & 0,729 & 0,159 & $0,006)^{2+}$ & 2,073 & $107,3 \%$ \\
\hline \multicolumn{6}{|l|}{ Gênero (referência: Feminino) } \\
\hline Masculino & $0,17 \mathrm{~A}$ & 0.141 & 0.218 & 1.190 & $19 \%$ \\
\hline \multicolumn{6}{|l|}{ Idade (referência: $16-24$ ) } \\
\hline $25-34$ & $-0,015$ & 0,211 & 0,972 & 0.985 & $-1.5 \%$ \\
\hline $35-14$ & $-0,348$ & 0,234 & 0,138 & 0,706 & $-29,4 \%$ \\
\hline $45-59$ & $-0,022$ & 0,235 & 0.925 & 0,978 & $-2,2 \%$ \\
\hline 60 ou mais & 0,189 & 0,278 & 0,497 & 1.208 & $20.8 \%$ \\
\hline \multicolumn{6}{|c|}{ Instruçào (referência: até primário incompletor } \\
\hline Primário completo & $-0,286$ & 0,246 & 0,245 & 0,751 & $-24,9 \%$ \\
\hline Fundamental incompleto completo & $-0,122$ & 0,214 & 0.570 & 0,886 & $-21,4^{4}$ \\
\hline Médio incompleto/ completo & $-0,487$ & 0,227 & $0,032^{* *}$ & 0,615 & $-38,5 \%$ \\
\hline Superior incompleto ou mais & $-1,341$ & $0,3+5$ & $0,000^{* *}$ & 0,262 & $-73,8 \%$ \\
\hline \multicolumn{6}{|l|}{ Renda familiar (referência: Baixa) } \\
\hline Mêdia & 0,102 & 0,159 & 0,522 & 1,107 & $10,7 \%$ \\
\hline Alta & 0,147 & 0,217 & 0.500 & 1,158 & $15,8 \%$ \\
\hline \multicolumn{6}{|l|}{ Cor da pele (referêncta: Pretos) } \\
\hline Pardos & 0,733 & 0,251 & $0,004^{20}$ & 2,082 & $108,2 \%$ \\
\hline Brancos & 0,766 & 0,257 & $0.003^{37}$ & 2,150 & $115 \%$ \\
\hline \multicolumn{6}{|c|}{ Exposição à TV em geral (referência: Nâo assiste até 1 hoña por dia } \\
\hline De 2 até 3 horas & 0,232 & 0,171 & 0,175 & 1,261 & 126,196 \\
\hline Até 4 horas ou mais & $-0,007$ & 0,200 & 0,971 & 0,993 & $-0,7 \%$ \\
\hline \multicolumn{6}{|c|}{ Atencao a noticias sobre politica na TV (referencia: Nenbuna) } \\
\hline Pouca & $-0,212$ & 0,169 & 0,211 & 0.809 & $-19,1 \%$ \\
\hline Alguma muita & $-0,325$ & 0,179 & $0.069^{+}$ & 0.722 & $-27,8 \%$ \\
\hline \multicolumn{6}{|c|}{ Exposiçào ao JN (refência: Näo assistel 1 dia na semana) } \\
\hline 2 ou 3 dias & $-0,059$ & 0,210 & 0.777 & 0,942 & $-5,896$ \\
\hline De 4 a todos os dias & 0,045 & 0,201 & 0,822 & 1.046 & $4,6 \%$ \\
\hline \multicolumn{6}{|c|}{ Procurou servico público ano passado (referencias năo) } \\
\hline $\operatorname{sim}$ & $-0,403$ & 0,152 & $0,008^{* *}$ & 0,669 & $-33,1 \%$ \\
\hline \multicolumn{6}{|c|}{ Utilizou servicos de hospital público (referência: não) } \\
\hline Sim & 0,164 & 0,172 & 0,341 & 1,178 & $17,8 \%$ \\
\hline \multicolumn{6}{|c|}{ Utilizou servicos de policia (referência: não) } \\
\hline Sim & 0,026 & 0,182 & 0,887 & 1,026 & $2,6 \%$ \\
\hline \multicolumn{6}{|c|}{ Utilizou servicos de (ransporte publico (referência: hăo) } \\
\hline Sim & $-0,103$ & 0,169 & 0.544 & 0,902 & $-9,8 \%$ \\
\hline
\end{tabular}

Fonte: A desconfiança dos cidadãos das instituições democráticas/2006

Resta comentar ainda um achado relevante do segundo modelo analisado: uma das variáveis relativa ao contato pessoal ou acesso direto com os serviços públicos obteve significância estatística, indicando que esse é quesito que diferencia a percepção do cidadão. Aqueles que afirmam ter procurado no ano anterior algum tipo de serviço público - seja ele de qualquer esfera governamental (federal, estadual ou municipal) - apresentam 33,1\% menos chance de estarem entre os satisfeitos. Ou seja, ter contato com os serviços públicos favorece percepções mais negativas. É o contrário dos resultados obtidos pelo instituto Mori (2003) para o Reino Unido. A avaliação geral mais 
negativa dos serviços públicos brasileiros contribui para entender essa evidência. É possível pensar que, ao ter contato com o serviço público de qualidade relativamente rebaixada existente no país, o cidadão desenvolve percepção pior - e não melhor - dos préstimos das agências estatais.

\section{Considerações finais}

No balanço geral das evidências, a avaliação dos serviços públicos mostrou ter se tornado mais favorável entre os anos 1990 e a década passada. Os índices positivos passaram a superar os negativos, tanto em avaliações genéricas (para o conjunto dos serviços) quanto em termos específicos (para setores determinados ou a esfera municipal). Ainda assim, o cidadão julga que os serviços deixam muito a desejar quando comparados a um "padrão ideal" ou se tomados como contrapartida de impostos tachados de "muito caros" por 3 em cada 4 brasileiros.

Quando passamos da leitura da situação para a investigação dos determinantes da satisfação com os serviços públicos, identificamos que são os setores mais escolarizados e informados os que avaliam mais negativamente os serviços prestados, o que sugere que a mobilização cognitiva ampliada favorece uma relação de maior ceticismo diante da ação do Estado. Essa síndrome negativista em relação aos serviços também é encontrada entre aqueles que apresentam maior interesse por notícias sobre política. Já o contato com serviços públicos mostrou-se um elemento que pouco incorpora poder explicativo, com apenas uma associação estatisticamente significante nos dois modelos postos em análise. Cabe ressaltar, contudo, que são poucas as variáveis que medem esse aspecto e, além disso, elas apenas se referem a três tipos de serviços, enquanto o índice de satisfação incorpora oito. Faz-se necessário ampliar informações a respeito para termos maior esclarecimento analítico sobre essa relação.

Por fim, destacamos que investigações sobre as orientações individuais em relação aos serviços públicos - em diversos aspectos - precisam ser ampliadas porque, num país dito como democrático, é essencial que se saiba o quanto os cidadãos estão satisfeitos ou não com serviços que visam a garantir sua sobrevivência ou melhorar a qualidade de vida. No momento, as tentativas de aprofundar estudos nessa direção esbarram em limitações devido ao estreito acervo de informações disponíveis.

(Artigo recebido em agosto de 2012. Versão final em dezembro de 2012).

\section{Notas}

1 Além do governo central, o País possui 27 estados, um Distrito Federal com autoridade assemelhada à dos estados e mais de 5.500 municípios.

2 O enunciado das questões é o seguinte:

- "De um modo geral, em termos de ótimo, bom, regular, ruim ou péssimo, como você avalia os seguintes serviços públicos mantidos pelo governo: habitação, polícia, etc.?” (1993). 
- "Como você avalia os serviços públicos do País? Em relação ao serviço de habitação, polícia, etc.), você acha que é ótimo, bom, ruim ou péssimo?” (2006).

Em ambos os casos, mantivemos a resposta "regular" e fizemos junções de respostas nos demais casos, criando as seguintes categorias:

"ótimo" + "bom" = "avaliação positiva";

"péssimo" + "ruim" = "avaliação negativa"

3 Todos os quadros, gráficos e tabela presentes neste artigo - com exceção do Gráfico 5 para o tipo de valor utilizado - expõem valores em formas de percentuais e desconsideram as respostas "não sei" e "não quero responder" dadas pelos entrevistados, excluindo-as do conjunto de respostas válidas.

4 O enunciado das questões é o seguinte:

- Eseb 2002: "Vou citar alguns serviços e gostaria que o (a) senhor (a) desse uma nota de 0 a 10 para dizer o quanto está satisfeito com cada um deles. De 0 a 10, que nota o senhor (a) dá para (coleta de lixo, polícia, etc.).

- Barômetro das Américas 2008 e 2010: O (a) senhor (a) diria que os serviços que a prefeitura oferece (coleta de lixo, iluminação nas ruas,..) para as pessoas são... muito bons/ bons/ nem bons nem maus (regulares)/ maus/ muito maus (péssimos).

Em todos os casos, mantivemos a resposta "regular" e fizemos junções de respostas nos demais casos, criando as seguintes categorias:

"ótimo" + "bom" = "avaliação positiva";

"péssimo" + "ruim" = "avaliação negativa".

5 Descrição da variável presente no Eseb 2002: "Agora, imagine um serviço público ideal, perfeito, que seria nota 10 , e um serviço público longe do ideal, que seria nota 0 , que nota de 0 a 10 o (a) senhor (a) daria para o serviço público brasileiro?”.

6 O índice que usou como variável dependente contemplava questões como a concordância com a frase "políticos muito honestos não sabem governar" ou "os partidos só servem para dividir as pessoas".

7 Trata-se do principal telejornal do País. Em 2006, 52\% dos entrevistados no survey "Desconfiança nas instituições democráticas" assistiam ao Jornal Nacional quatro vezes ou mais por semana e $89,2 \%$ assistiam ao menos uma vez por semana.

8 A análise fatorial objetiva prover descrições simples de inter-relacionamento, correlações e covariâncias entre as variáveis. Ela torna visível a observação de quais variáveis possuem associações entre si e as organizam em fatores. Em cada fator, temos as variáveis mais associadas entre si e a intensidade dessa associação, que se mostrará forte, mediana ou fraca de acordo com a magnitude de sua carga estatística, geralmente compreendida entre - 1 e 1 (KIM; MUELLER, 1978).

9 Nos quadros 1 e 2, o efeito percentual significa o resultado da equação (razão de chance - 1) * 100 e indica qual o diferencial em relação à categoria de referência. 


\section{Referências bibliográficas}

BONIFÁCIO, Robert. Desempenho governamental e apoio à democracia no Brasil. Dissertação de mestrado, Campinas, Instituto de Filosofia e Ciências Humanas, Universidade Estadual de Campinas. 2009. Disponível em:<http://www.opiniaopublica. ufmg.br/ biblioteca/dissertacao_robert.pdf $>$. Acesso em 19/03/2012.

Cappella, Joseph; Jamieson, Kathleen. Spiral of cynicism: the press and the public good. New York: Oxford University Press, 1997.

Costello, Ana; Osborne, Jason. Best practices in exploratory factor analysis: four recommendations for getting the most from your analysis. Practical Assessment, Research and Evaluation, v.10, $\mathrm{n}^{\circ}$ 7, 2005.

Cronbach, L. J. Coefficient alpha and the internal structure of tests. Psychometrika, v.16, $\mathrm{n}^{\circ} 3,1951$.

DiAmond, Larry; Morlino, Leonardo. The quality of democracy: an overview. Journal of Democracy, v. 15, no 4, 2004.

FARIA, Vilmar. A conjuntura social brasileira: dilemas e perspectivas. Novos Estudos Cebrap, 33, 1992.

Figueiredo, Argelina; Torres, Haroldo; Bichir, Renata. A conjuntura social brasileira revisitada. Novos Estudos CEBRAP, 75, 2006.

FOWLER JR, Floyd. Improving survey questions: design and evaluations. Londres: Sage Publications, 1995.

Garson, David. Scales and Standard Measures. In: Garson, David (ed). Statnotes: topics in multivariate analysis, 2011. Disponível em http://faculty.chass.ncsu.edu/garson/ pa765/standard.htm. Acesso em 07/02/2012.

. Factor Analysis. In: Statnotes: topics in multivariate analysis, 2010. Disponível em http:/ / faculty.chass.ncsu.edu/garson/pa765/statnote.htm. Acesso em: 13/04/ 2010.

Graber, Doris. Mass Media and American Politics. Washington: CQ Press, 1989.

IngleHART, Ronald. Postmodernization Erodes Respect for Authority, but Increases Support for Democracy. In: Norris, Pippa (ed). Critical citizens: global support for democratic government. Oxford: Oxford University Press, 1999.

Klapper, Joseph. The Effectiveness of Mass Communication. In: Graber, Doris (ed). Media power in politics. Washington: CQ Press, 1990.

LupIA, Arthur. How elitism undermines the study of voter competence. Paper prepared for Critical Review Issue on Civic Competence, 2005.

Mesquita, Nuno Coimbra. Mídia e Democracia no Brasil: Jornal Nacional, Crise Política e Confiança nas Instituições. 2008. Tese de doutorado, Faculdade de Filosofia, Letras e Ciências Humanas, Universidade de São Paulo.

Moisés, José; CARneiro, Gabriela. Democracia, desconfiança política e insatisfação com o regime: o caso do Brasil. In: MoIsés, José (ed). Democracia e confiança: por que os cidadãos desconfiam das instituições públicas? São Paulo: Edusp, 2010. 
MorI. Trust in public institutions. New findings: national quantitative survey. Londres: Audit Comission, 2003.

Newton, Kenneth. Mass media effects: mobilization or media malaise? British Journal of Political Science, v. 29, no 4, 1999.

Norris, Pippa. Does television erodes social capital? A reply to Putnam. PS: Political Science and Politics, v. 29, no 3, 1996.

. The Growth of Critical Citizens? In: NORRIS, Pippa (org). Critical Citizens: global support for democratic government. Oxford: Oxford University Press, 1999. . A Virtuous Circle: Political Communications in Post-Industrial Democracies. Cambridge: Cambridge University Press, 2000.

Patterson, Thomas. Out of order. New York: Vintage Books, 1993.

Popkin, Samuel. The reasoning voter: communication and persuasion in presidential campaigns. Chicago: University of Chicago Press, 1994.

Putnam, Robert. Tuning in, Tuning out: The Strange Disappearance of Social Capital in America. PS: Political Science \& Politics, v. 27, no 4, 1995.

. Bowling alone: the collapse and revival of American community. New York, Simon and Schuster, 2001.

Robinson, Michael. Public affairs television and the growth of political malaise: the case of 'The selling of pentagon'. American Political Science Review, 70, 1976.

SCHLegel, Rogério. Mídia, confiança política e mobilização. Dissertação de mestrado, Faculdade de Filosofia, Letras e Ciências Humanas, Universidade de São Paulo, 2005. Disponível em <www.teses.usp.br/teses/disponiveis/8/8131/tde-12082011-131211/ptbr.php>. Acesso em 19/01/2012. 


\section{Resumo - Resumen - Abstract}

\section{Panorama e determinantes da satisfação com os serviços públicos no Brasil Robert Bonifácio e Rogério Schlegel}

A percepção do cidadão sobre a qualidade dos serviços públicos é dimensão que merece ser avaliada por ser indicador do nível de responsividade do Estado e da qualidade da democracia. No Brasil, entretanto, são raros estudos com esse objeto. O artigo utiliza surveys com representatividade nacional, aplicados entre 1993 e 2010, para medir a satisfação com os serviços públicos e buscar seus determinantes. Os dados empíricos mostram melhora na avaliação no período observado, sugerem que os níveis de escolaridade e informação são os preditores mais consistentes da satisfação com os serviços públicos e que, no contexto brasileiro, o contato direto pode impactar negativamente a percepção sobre eles.

Palavras-chave: serviços públicos; Estado; democracia; cidadão crítico

\section{Panorama y determinantes de la satisfacción con los servicios públicos en Brasil} Robert Bonifácio y Rogério Schlegel

La percepción de los ciudadanos sobre la calidad de los servicios públicos es la dimensión que merece ser evaluada por un indicador del nivel de capacidad de respuesta del Estado y la calidad de la democracia. En Brasil, sin embargo, hay pocos estudios de este objeto. Este artículo utiliza encuestas representativas a nivel nacional, aplicadas entre 1993 y 2010 para medir la satisfacción con los servicios públicos y buscar sus factores determinantes. Los datos empíricos muestran una mejora en la evaluación en el período observado, sugieren que los niveles de la educación y la información son los predictores más consistentes de la satisfacción con los servicios públicos y, en el contexto brasileño, el contacto directo puede influir negativamente en la percepción de ellos.

Palabras clave: Utilidades; Estado; democracia; el ciudadano crítico

\section{An overview of satisfaction with public services in Brazil and its determinants Robert Bonifácio and Rogério Schlegel}

Citizen's perception about the quality of public services is a dimension that must be evaluated as an indicator of the level of responsiveness of State and the quality of democracy. However, studies with this subject are rare in Brazil. The paper uses surveys representing the national population, applied between 1993 and 2010, to measure the satisfaction with public services and investigates its determinants. Empirical data show improvement in evaluations in the observed period and suggest that educational and information levels are the most consistent predictors of public service satisfaction and that, in the Brazilian context, the direct contact may impact negatively the perception about them.

Keywords: Public services; state; democracy; critical citizens 
Robert Bonifácio

Doutorando em Ciência Política pela Universidade Federal de Minas Gerais (UFMG).Contato: robertbonifacio@hotmail.com Rogério Schlegel

Doutor em Ciência Política pela Universidade de São Paulo (USP) e pós-doutorando vinculado ao Centro de Estudos da Metrópole/ Centro Brasileiro de Análise e Planejamento (CEM/ Cebrap).Contato: rschlegel@uol.com.br 